Purdue University Purdue e-Pubs

\title{
(POSTER) Deepening Engineering Design Experience: A Novel Approach to Senior Design
}

Donald Peterson

Northern Illinois University

Mansour Tahernezhadi

Northern Illinois University

Abul Azad

Northern Illinois University, aazad@niu.edu

Follow this and additional works at: https:// docs.lib.purdue.edu/aseeil-insectionconference

Part of the Engineering Education Commons

Peterson, Donald; Tahernezhadi, Mansour; and Azad, Abul, "(POSTER) Deepening Engineering Design Experience: A Novel Approach to Senior Design" (2019). ASEE IL-IN Section Conference. 10.

https://docs.lib.purdue.edu/aseeil-insectionconference/2019/posters/10

This document has been made available through Purdue e-Pubs, a service of the Purdue University Libraries. Please contact epubs@purdue.edu for additional information. 
Deepening Engineering Design Experience: A Novel Approach to Senior Design

Donald Peterson, Mansour Tahernezhadi, and Abul Azad

College of Engineering and Engineering Technology, Northern Illinois University

\section{Introduction}

This project advances a new framework for a senior design course in order to deepen engineering design experience for engineering students. The proposed framework for the new senior design course whil retains the traditional topics such as problem identification, conceptual design and analysis, prototyping and the preparation of a work schedule required to carry out the project, it fosters an early in the cycle start, typically after the week 6 , towards the design conceptualization and prototyping in the first academic semester. This is in a stark contrast with traditional practices where the design conceptualization and prototyping largely takes place in the second academic semester for a disjointed two semester long typical senior design course. In addition, the new framework will involve the implementation of a variety of design topics including: design and/or programming of a device, mechanical system, electrical system, process, or algorithm. It will also focus on aspects of the overa engineering design process including: (1) working interdisciplinary teams, (2) project planning and
scheduling (e.g., timelines), (3) technical report writing scheduling (e.g., timelines), (3) technical report writin (4) oral presentations, (5) ethics in design,(5) safety, liability, and (6) impact of economic constraints, marketing.

\section{Distinct Features}

The new senior design course is different in many respects with the following salient features: 1) one academic year long design course consisting of two consecutive three credit hour senior design courses in the Fall and Spring semesters, respectively; 2) early initiation of the team-based design project within the first six weeks of the start of the first course in the Fall semester; 3) formation of interdisciplinary student teams for combined electrical and mechanical designoriented projects; 4) mentoring by practicing engineers along with faculty supervision on industry sponsored design projects; 5) each design team has an assigned faculty mentor and graduate teaching assistance; and 6) a newly dedicated space named "Senior Design Studio" with is provided for student teams to construct and test their designs. The Senior Design Studio also features availability of smart conference rooms for faceto-face or virtual mentoring by industry partners.

\section{Project Team and Supervision}

At the beginning of the semester, the course syllabus is circulated within the students who are enrolled for the senior design course. As early as the second week, students are provided with a booklet of potential senior design project abstracts either proposed by industry partners of campus-wide faculty. Each proposer has to do 5 minute pitch on their project to the students in order to attract a potential student team for their project. Depending on the nature of their project, students will selfassemble to form a team of 3 to 4 members. A faculty mentor is matched to the team depending on the nature of the project. If the project calls for expertise both from electrical and mechanical engineering, the the emerged team will be an interdisciplinary team. Each project team is asked to prepare a detailed project proposal with an associated timeline of majo deliverables. The detailed project proposal should allow for an optimal design and three accompanying along with flexibility to the design process.

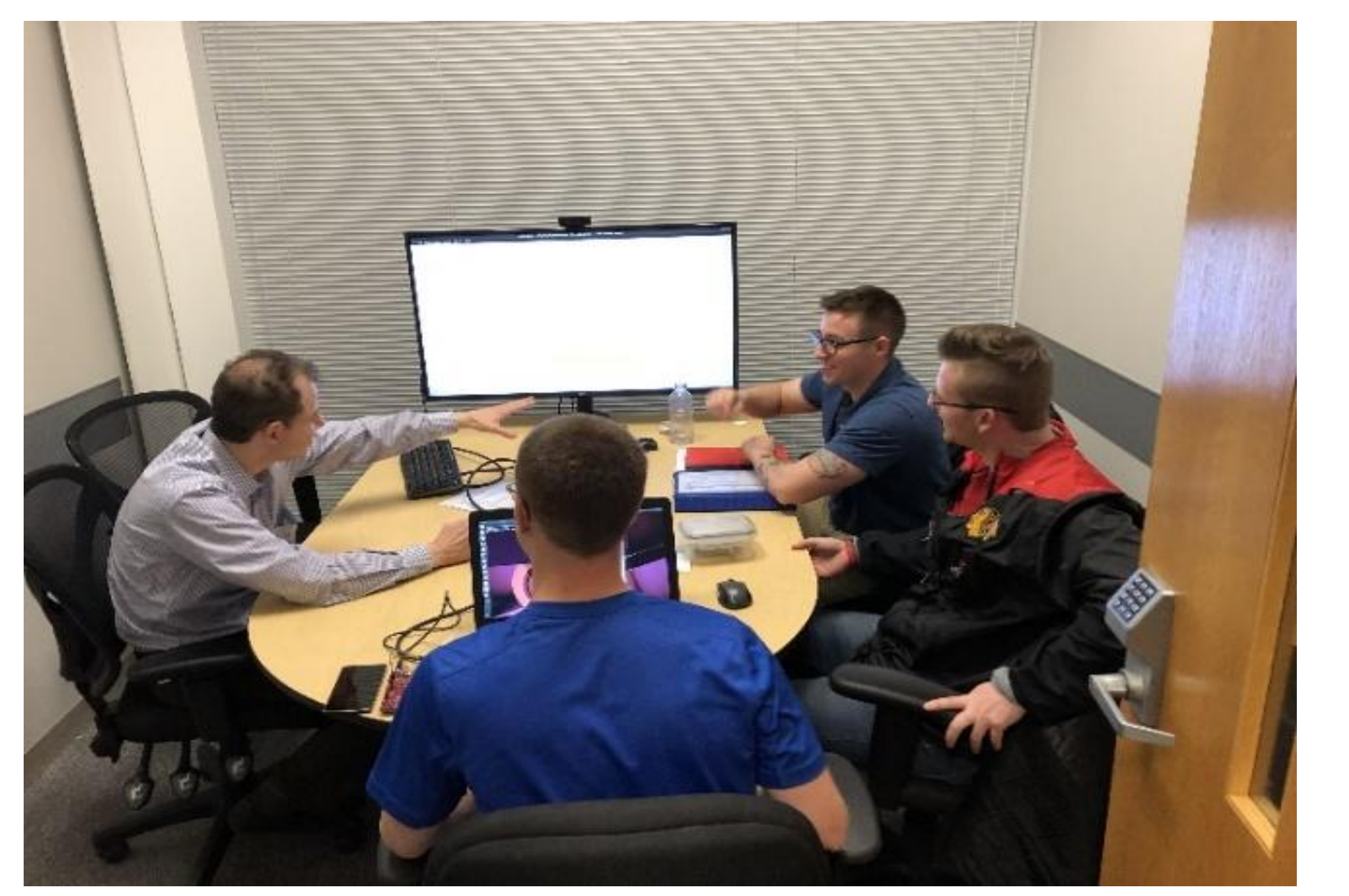

Figure 1: A Weekly meeting session

Students are also be able to propose a team project; however, student-proposed projects need to be pitched and approved by the lead course instructor before they are allowed to be undertaken. Students are allowed to select eammates. A balance among capabilities is strongly recommended in order to create a eam that is multidisciplinary in nature and capable to complete the project successfully. The grading components involvesquizzes/attendance, design ideas, weekly activities, client input, final report, final presentation, self and peer evaluation. Each student fill the form individually to evaluate his/her task as well as evaluate the team members. The faculty advisor review these evaluation forms and take necessary action if needed to make sure that each member putting their effort to ensure the design success.

\section{Senior Design Studio}

To facilitate the senior design project activities, a dedicated design studio is developed and made available for the senior design students (Figure 2). The studio provides a workbench area for each group. Each group is assigned a workbench for the duration of the toolbox, a computer, electronic test equipment, and data acquisition system. The students have 24/7 access to the studio using their university ID card that allows the authority to monitor the access as well as the level of utilization of the facility. The studio is monitored by a network of video cameras to address safety and security issues. In addition to the individual toolbox and other test items students are provided with a small maker's space which can be utilized to complete small scale machining activities (Figure 3 ).

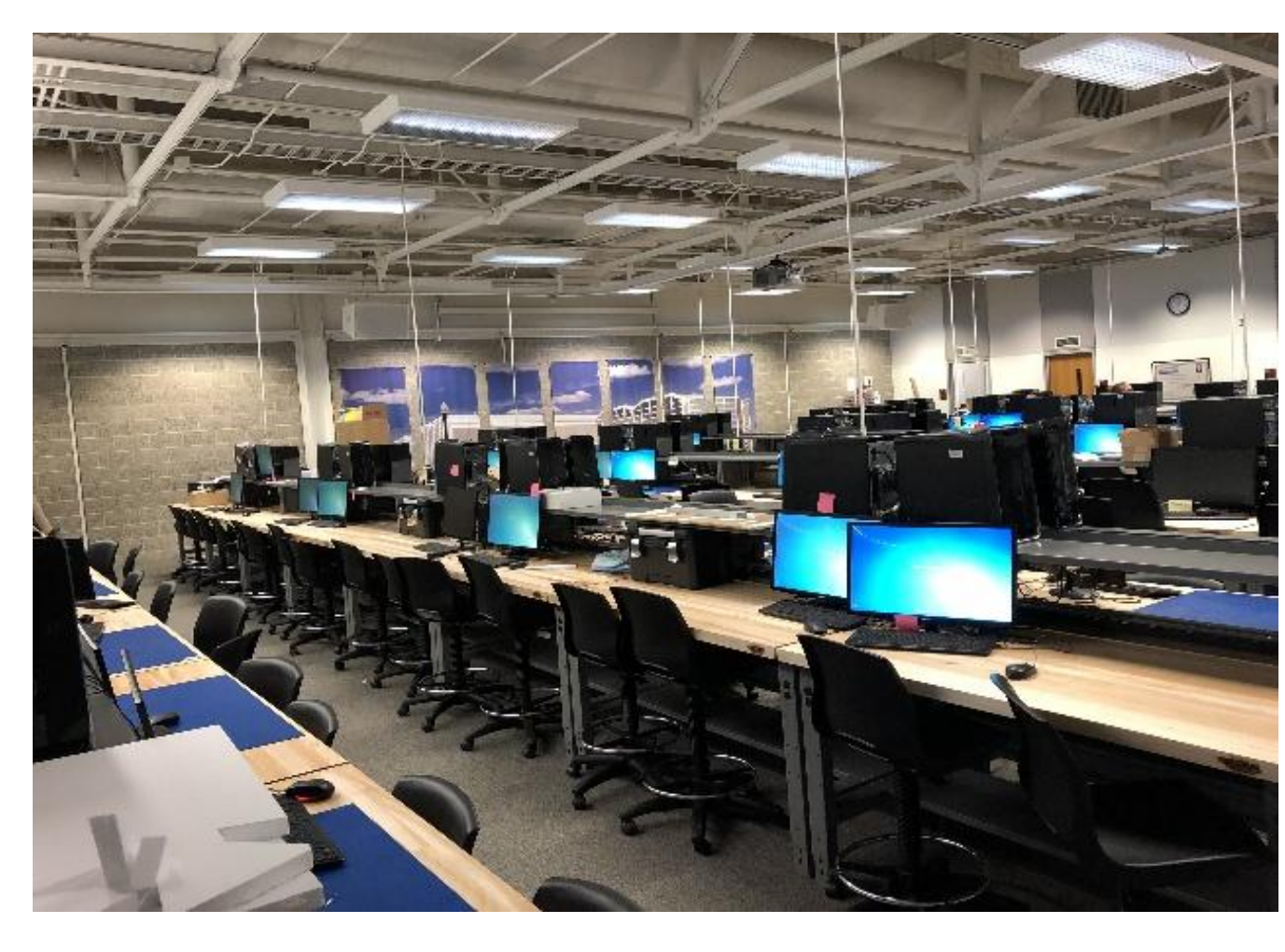

Figure 2: Senior design studio

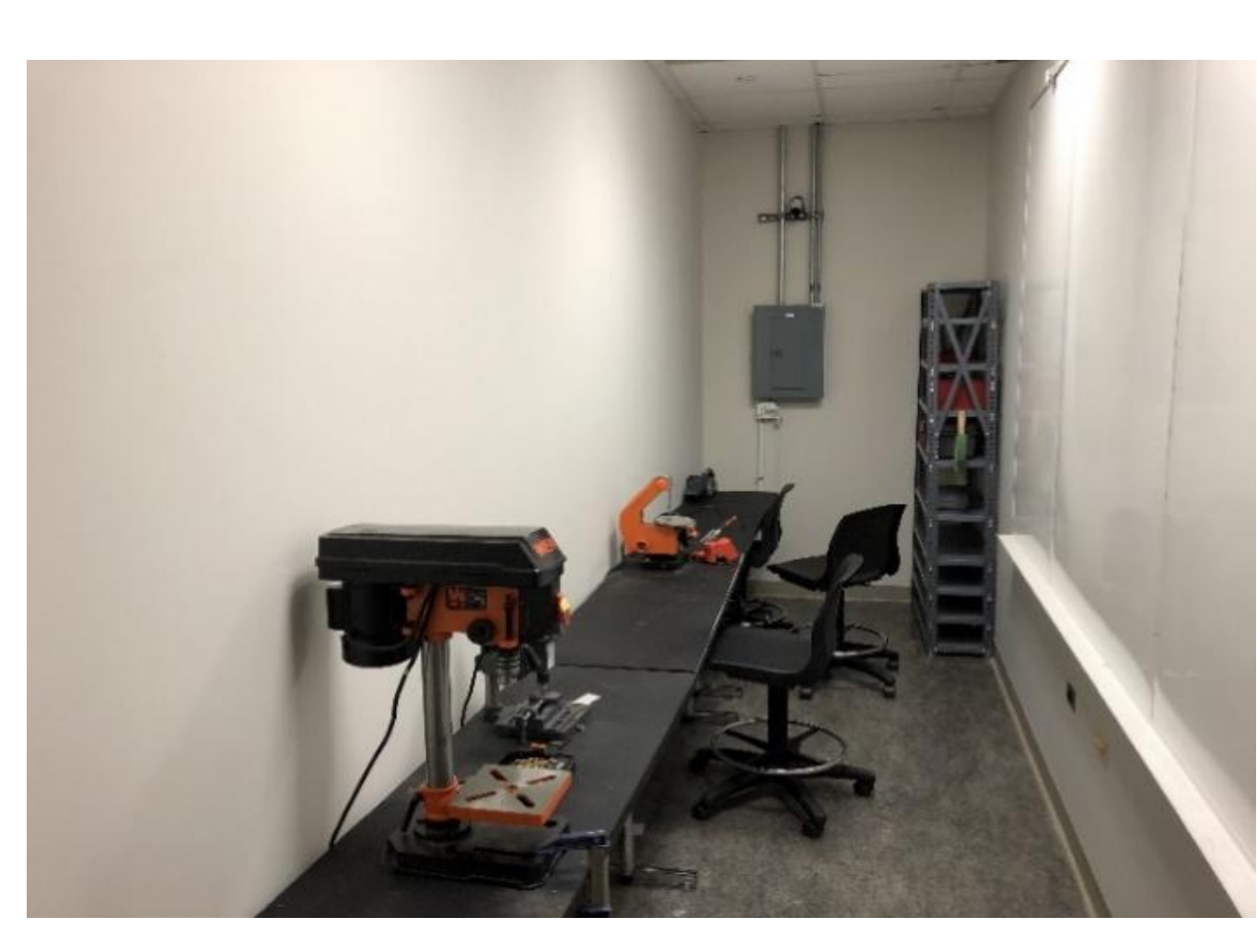

Figure 3: Dedicated makers space.

\section{Meeting Course Requirements}

During the first semester of the course the project groups are mentored to become cognizant of main design conceptualization requirements. Students are intentionally directed for literature search and patent search, so that they can aware of the current knowledge and practices enabling them to highlight their design novelty in comparison to the existing designs. They also do the market and cost analysis as well as highlight the ethical aspects of the design. In addition, they do an engineering analysis to establish optimality of the design. The engineering analysis should warrant the
establishment of three alternative designs.
Based on go, no-go emerging situations associated with optimal design, the alternative designs can help to further inform the design process in terms of having a "fall back" position based on objections emerging from cost or manufacturability point of view. During the first semester, the class meets once a week for a three hou session. The class involves lecture by the lead instructor as well as presentation by guest speakers from industry. The lectures are mainly focused on discussing course requirements and deliverables, time and project-management, and literature search. In addition to attending lectures and working on projects, each team meets individually with their faculty advisor and the team TA for weekly meetings. During the second semuster, there are monly tho three lecture sessions duning the beghe on the semester so that design

\section{Lessons Learned}

The newly formed senior design course was offered for first time during the Fall 2018 and a number of issues were identified in terms of what worked and not worked. The major issue was the change of culture during the first in terms of design activities, organized weekly meeting with faculty, project pitch days, project selection and team formation. Given the new relationship with industries for this kind of venture, the engagement from industries was not as expected in terms of their participation during the pich day and their documentation on the design requirements. This in turn introduced some late start of actual design activities, since the course was offered first time in Fall 2018 semester, we are still in process of gathering data. The students from the first course have now been moved to the second semester. The authors are planning to present a more comprehensive data driven findings after the completion of cycle.

\section{Conclusions}

The paper presented the structure of a newly designed senior design course that deepens the engineering design experience through weekly progress monitoring inclusion of interdisciplinary student groups,

engagement from industry and active engineering faculty. The authors are planning to report the full finding after the completion of the course sequence.

\section{Contacts}

- Dr. Donald Peterson

- Dr. Mansour Tahernezhadi 